\begin{tabular}{|l|l|}
\hline$F M-2$ & 303 \\
\hline
\end{tabular}

$r$
MILITARY TECHNICAL COLLEGE

CAIRO - EGYPT

\section{NON-NEWTONIAN FLUIDS FLOW THROUGH DIFFUSERS} \\ B.A. KHALIFA ${ }^{*}$, K.A. IBRAHIM ${ }^{* *}$ and M.H. EMBABY $Y^{* *}$
}

. 
The study of Non-Newtonian fluid flow through pipes with variable crosssection is of paramount importance in numerous engineering applications. Especially those fluids which are handled on a large scale in many industries such as; petroleum; paints, paper anỏ pölymerccnversion.

The behaviour of Nor-Newtonian fluid flow through pipes with constant cross-section has previously been studied by $(1,2,3)$. Experimental studies (4) have been made for determining the discharge coefficient of orifice Non-Newtonian flow meter mounted in a straight circular pipe. Astarita ano Peluso (5) measured excess pressure drops for laminar flow of NonNewtonian liquids, both weakly and hiqhly elastic. Their results show that, the dimensionless pressure drof is inversely proportioral to the Reynolds number, the ccnstant of proportionality being a function of the flow index. Kato and Shibanuma (6) made an expeimental stuảy on diverging and corverging flow of dilute folymer solutions. They used folyethylene oxide (PEO-18) and pclyacrylamide (AP-30) in water as polymer solutions. The main objactive of their experiments was to investigate the drag reduction phenomenon in three tapered tukes. They founo that in a converging flow, a remarkable drag rediction such as a pipe flow is not recognized. In a diverging flows they found also that with an increase in the ccncentration to 100 ppm pressure reccvery beccmes smaller than water flow alore. The effect of drag reducing additives ufon the flowith pressure gradient (positive ano’ negative) has been studied by El-haroun [7].

From the above literature revien, it is clear that the kehaviour of NonNewtonian fluid flow through diffusers needs further analysis. The main object of the present investigation is to determine the effect of polymer concentration, the flow Reynolds number ano the diffuser gecmetry on the behaviour of Non-Newtonian fluids flow through difiusers.

\section{NOMENCLATURE}

CF: $\quad$ Static pressure loss coefficient $\left(\Delta P / \rho_{1} V_{1}^{2}\right)$

d : $\quad$ Diffuser diameter.

K : $\quad$ Consistency coefficient.

L : Diffuser length

$\mathrm{n}$ : $\quad$ Flow kehavinir index

Q: $\quad$ Volume flow rate

R : Reynolds num.ter

$\mathrm{V}^{\mathrm{e}}$ : $\quad$ Fluid velocity

$\Delta \mathrm{h}$ : Pressure head difference ketween the inlet and outlet cross-sections of the diffuser.

$\Delta \mathrm{P}: \quad$ Pressure difference between the inlet and cutlet crosssections of the diffuser.

$\theta$ : Half angle cf diffuser

$\rho: \quad$ Fluid density.

\section{SUBSCRIPTS}

1 : Ccnditions at diffuser inlet.

2 : $\quad$ Conditions at diffuser olitlet.

\section{APPARATUS AND MEASURING TECHNIQLES}

A schematic diagram of the test rig is shown in Fig. (1). The test fluid 
flows from the upper main tank (1), $(1 \times 1 \times 1 \mathrm{~m})$. to the cverflow tank (2), $(0.5 \times 0.3 \times 0.4 \mathrm{~m})$ which is used to ensure a ccnstant head allover the expeiments. The test fluid flows from the cverflow tank (2), through the test section, to the ccllecting tank (5), (1.5 × $1.5 \times 0.5 \mathrm{~m})$. The flow rate is changed by using the control valve after the test section. A centrifugal pump (6) is used for lifting the testing fluid to the upper tank.

\subsection{Test Section:}

Five circular diffusers, Fig. (2), are used as a test section. The detailed dimensions of these diffusers are indicated in this figure.

The pressure difference between inlet ano outlet cross sections of diffusers was measured, usina U tuke manometer (4); Fig. (1), at different flow rates and for different values of C.M.C. concentrations.

\subsection{Measurement of Rhecloqical Properties of The Non-Newtonian Fluid:}

To measure the rheclogical properties (consistency ccefficient "K" and the flow index " $n$ ") of the carboxymethyl cellulose (C.M.C) solution, a capillary tube viscometer was used.

\section{RESULTS ANL DISCLSSION}

The working fluids used in the experimental work were water as the Newtonian fluid and different concentrations of carboxy-methyl-cellulose (C.M.C) solutions (10000, 20000, 30000 and 50000 F.P.m) as the dilatant Nor-Newtonian fluids.Degradation of polymer solutions and time effects were not determined as effective parameters due to high stability of the polymer solutions.

\subsection{Effect of Flow Eehaviour Index "n"}

Figs ( 3 and 4 ) show a representative selection of the measurements of the pressure difference retween inlet and cutlet cross-sections at different flow rates. The measurements were taken for water $(n=1)$ and for different concentrations of C.M.C. (different values of $n$ ). The effect of flow kehaviour index "n" or the roct of pressure difference head is shown in these figures. From these figures it can be seen that the total pressure difference increases with the increase of polymer ccncentration (increase the value $\mathrm{cf} n$ ) and volume flow rate. This meens that the diffuser losses decreases when the polymer ccncentratior. increases. From Fig. (3) it is clear that after $n=1.104$ (concentration 20000 p.p.m.), there is a reduction of diffuser pressure defference. This is due to an increase in the fluid visccsity and consequenly the risistance to the flow increases. Shibanume and Kato ( 6 ) folno that the folymer reduces the skin friction and in the same time enhances the separation and makes it occur at early cross-sectior cf the diffuser. As the separation increases the diffuser losses are increased. Fig. (5) show's a result for the diffuser No.1, which has a big angle and smell length as it is ccmpared with the cther diffusers. For this reason, it is clear from. this figure that, there is a reduction in the pressure difference ketween the inlet and cutlet cross-seçtions. This is die to the seraration which takes place early ( $\theta=12$ in this case). These results are ccnfirmed by El-haroin (7), who studied the effect of drag reducing additives on the flow with positive cr negative pressure gradient. . 


\subsection{Effect of Volume Flow Fate}

The effect of changing the volume flow rate (Raynolds number) on the pressure difference between the inlet and cutlet cross-sections of the tested diffusers is shown in Figs (3-7). Higher values of pressure difference are cbtained with higher flow rate which was expected die to the increase cf the fluid velocity. Also it is clear from these figures that the value $\operatorname{cf} \sqrt{\Delta h}$ or $\mathrm{C} p$ increases with the increase of volume flow rate.

\subsection{Effect of Diffuser Geometry}

The main gecmetrical parameters tested rere vere; the diffuser expansion angle and the diffusier lenqth, see Fig. (2). The cverall area ratio is equal to 2 for all diffusers. Figs ( 6 and 7 ) illustrate a selection of the experimental results showing the variation of static pressure rise ccefficient $C p$ with the diffuser inlet flow keynolds numker $\left(\operatorname{Re}_{1}\right)$. The values of Reynolds number, for the case cf Non-Newtonian flow, were calculated accoraing to the following relation;

$$
\operatorname{Re}_{1}=\frac{\rho_{1} \cdot v_{1} \cdot d_{1}}{K\left(8 \cdot v_{1} / d_{1}\right)^{n-1}}
$$

The measurements were taken for $n=1.104$ and $n=1.303$. It is clear that the static pressure rise ccefficient increases as the inlet keynolds numker increases. This is due to the increase of volume flow rate. The curves have the same treno for all tested diffusers. From these figures and with the relp of Fig. (2), it is noticed for each value cf $Q$ ano $n$ that the pressure rise coefficient decreases as the diffuser expansior. angle increases. This is due to the separation which takes place at early cross-section of the diffuser, as was disclissed in subsectior. 3.1. In general , from these figures it can be seen that, the poor performance of the $12^{\circ}$ half angle diffuser (diffuser No.1) is attributed to the fact that the diffuser sefarates badly at this range of Reynolds number. For all the corfiguratiors tested, the $4^{\circ}$ half angle diffuser (diffuser No.5) has the greatest pressure rise coefficient, whilst the $12^{\circ}$ half angle diffuser (diffuser No.1) has the lowest pressure rise coefficient.

\section{CONCLUSIONS}

The Non-Newtonian fluid flow through diffuser with different gearetries has been studied experimentally, for fluid flow keynolds numker range from 5000 to 21000 and polymer concentration from 10000 to 50000 p.p.m. The major conclusions and the results of this stuay are sumarized belon:

1. For diffusers having an expansion half angle less than cr equal to $10^{\circ}$, the pressure difference ketween the inlet ano clitlet crosssections of the diffuser increases with the increase cf polymer ccrcentration. On the other hand for $12^{\circ}$ half angle diffuser, this pressure difference was found to decrease with the increase cf polymer concentration.

2. Higher values of total pressure rise through diffusers are chtained, for all values of polymer concentrations, with higher values of volume flow rate.

3. The static pressure rise ccefficient increases as the Reynolds number increases. Also for all values of $Q$ and $n$ tested, the static pressure 
rise coefficient decreases as the diffuser expansion angle increases. For all the configurations tested, the $4^{\circ}$ half angle diffuser has the greatest pressure rise ccefficient, whilst the $12^{\circ}$ half angle diffuser has the lowest pressure rise coefficient.

4. For the Reynolds number range $\left(12000 \leq \mathrm{Re}_{1} \leq 21000\right)$ considered, the diffuser performance deteriorates with an increase in the inlet flow keynclds number. In Fig. (6), for example, taking the case of $n=$ $1.104, k=0.0084$ and area ratio 2 , by varying $R_{1}$ from 12000 to 21000, the following variations in CF occur :

(a) For the $4^{\circ}$ half angle diffuser, Cp increases from 0.65 to 0.68 .

(b) For the $6^{\circ}$ half angle diffuser, $\mathrm{Cp}$ increases from 0.6 to 0.65 .

(c) For the $8^{\circ}$ half angle diffuser, Cp increases from 0.56 to 0.6 .

(d) For the $10^{\circ}$ half angle diffuser, $\mathrm{Cp}$ increases from 0.315 to 0.34 .

(e) For the $12^{\circ}$ half angle diffuser, Cp increases from 0.23 to 0.26 .

It should be mentioned that there is no unique relation-ship between the Reynolds number and $\mathrm{Cp}=\Delta \mathrm{P} / \rho_{1} \mathrm{~V}_{1}^{2}$ ) and those values given akove are merely for illustration. This conclusion has been previously achieved by Livesey, et.al (8), for air flow through ccnical diffusers. The presert investiqation proves this conclusion in the case cf incompressible Non-Newtonian fluids flow through diffusers.

\section{RE FERENCES}

1. Kozicki, W., Chol, C.H. and Tiu, C., "Non-Newtonian flow in ducts of arbitrary cross-sectional shape"J. Ch. Eng. Science, Vol.. 21, P. 665,1966 .

2. Ernst, W. I., "Investigation of turbulent shear flow cf dilute aquecus CN.C solutions", AICHE Jcurnal, Vol. 12, 1966.

3. Meyer, W.A., "A correlation of the frictional characteristics for turbulent flow of dilute visccelastic Non-Newtonian fluids in pipes", AICHE Jcurnal, Vol. 12, 1966.

4. Bilgen, E.," On the crifjce flow cf dilute frclymer solutions", J.fluid Mech., Vol. 12, 1973.

5. Astarita, G. and Feluso, L. "Excess pressure drop in laminar flow through suaden contraction-Non-Newtorian liquids", Indus. \& Eng. Cr:er. fundamentals, Vol. 7, 1968.

6. Shibanuma, H. and Kato, H., "Diverging and ccnverging flows of dilute polymer solutions" Bull. of the JSME, Vol. 23, No. 181-16, P. 1148,1980 .

7. El-Haroun, A.A., "The effect of drag reducing additives uron the flow in nozzles and diffusers", M.Sc., Mech. Eng. Deft., Menolfia University, 1983.

8. Livesey, J.L. and cilikwe, A.O., " Som: $€$ ffects on canical diffuser performance of preceding rormal shock koundary-laver interaction" Proc. Instn. Mech. Engrs, Vol. 188, pc. $607-613,1974$. 


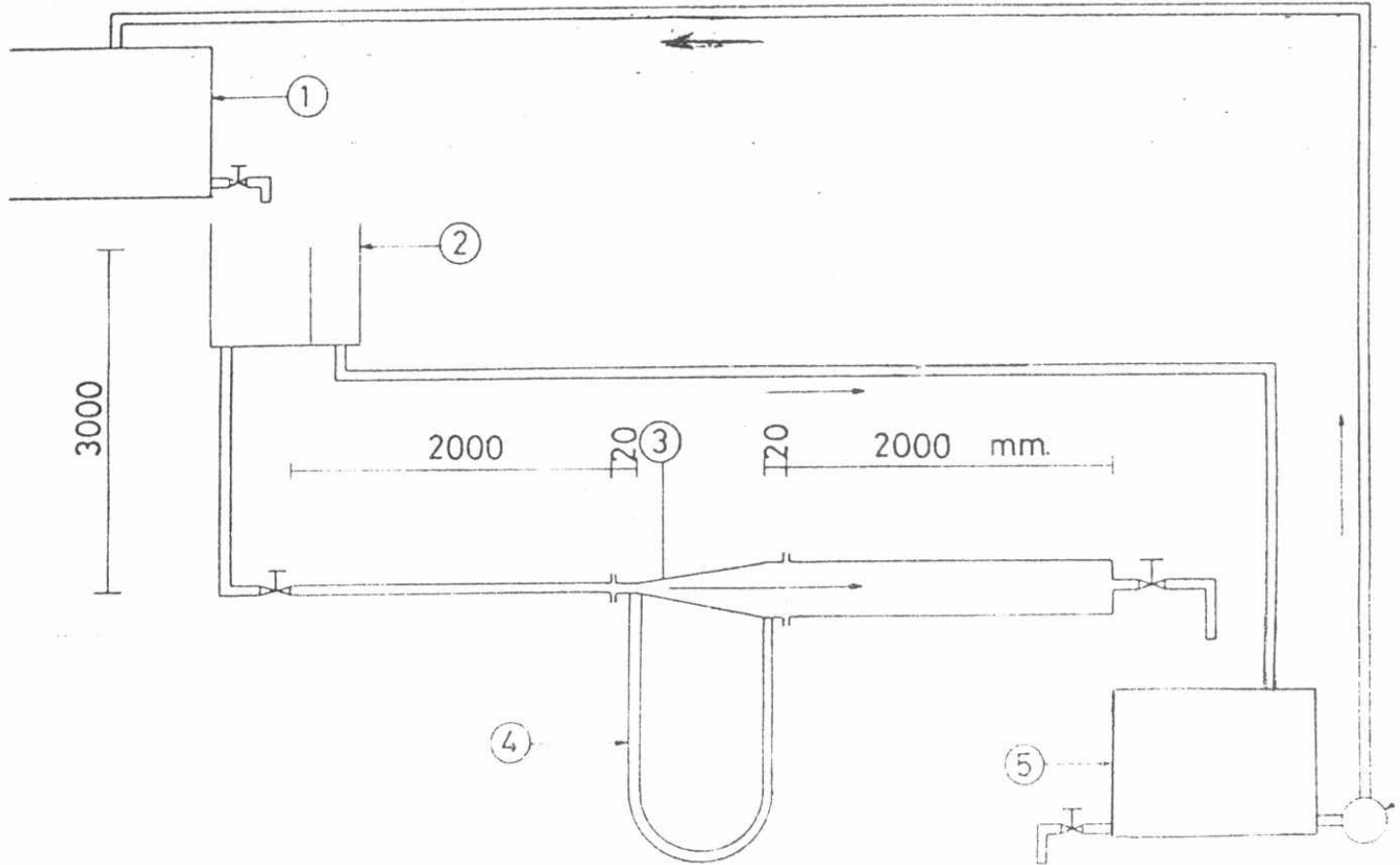

FIG(1) A SCHEMATIC DIAGRAM OF THE TEST RIG.

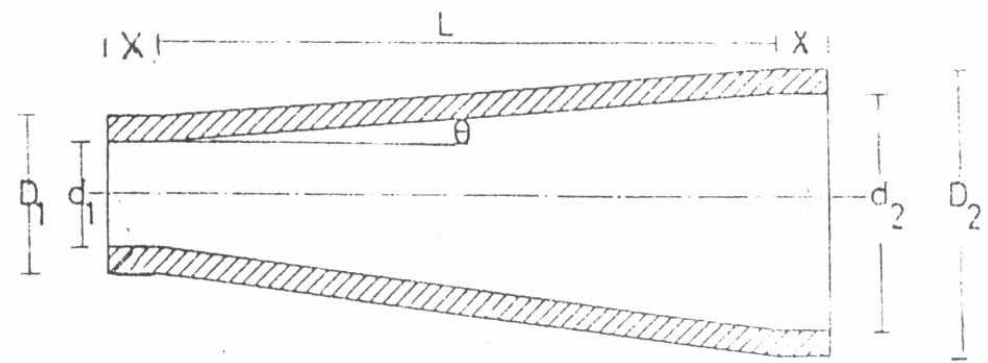

\begin{tabular}{|c||c|c|c|c|c|c|c|}
\hline $\begin{array}{c}\text { DIFFUSER } \\
\text { NO. }\end{array}$ & $\begin{array}{c}\mathrm{L}_{1} \\
\mathrm{~mm} .\end{array}$ & $\begin{array}{c}\mathrm{D}_{1} \\
\mathrm{~mm}\end{array}$ & $\begin{array}{c}\mathrm{d}_{1} \\
\mathrm{~mm} .\end{array}$ & $\begin{array}{c}\mathrm{D}_{2} \\
\mathrm{~mm}\end{array}$ & $\begin{array}{c}\mathrm{d}_{2} \\
\mathrm{~mm} .\end{array}$ & $\theta$ & $x$ \\
\hline 1 & 635 & 43 & 27 & 70 & 54 & $12^{\circ}$ & 20 \\
\hline 2 & 765 & 43 & 27 & 70 & 54 & $10^{\circ}$ & 20 \\
\hline 3 & 96 & 43 & 27 & 70 & 54 & $8^{\circ}$ & 20 \\
\hline 4 & 128 & 43 & 27 & 70 & 54 & $6^{\circ}$ & 20 \\
\hline 5 & 193 & 43 & 27 & 70 & 54 & $4^{\circ}$ & 20 \\
\hline
\end{tabular}

FIG (2) DIFFUSER GEOMETRY 


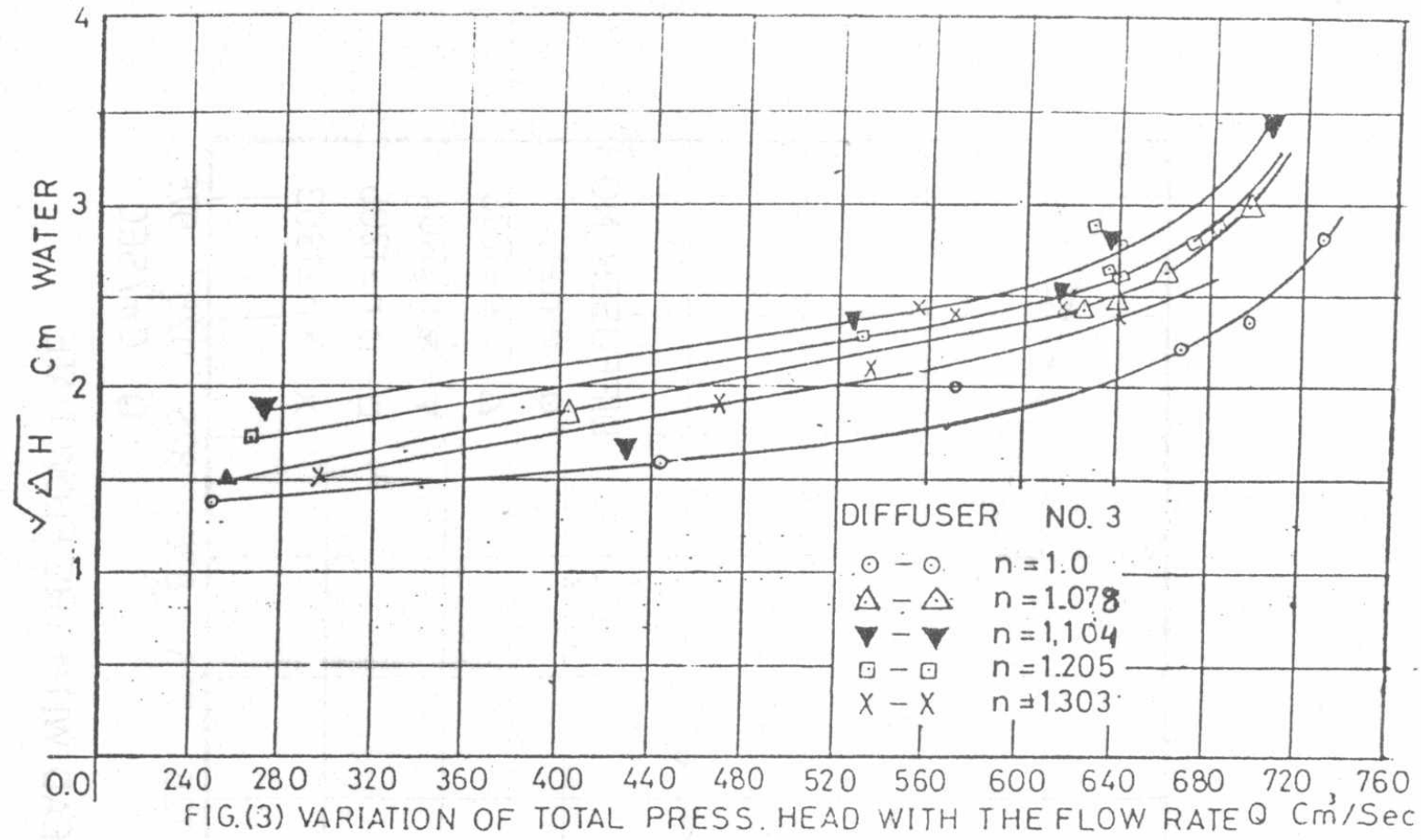

(EFFECT OF FLOW BEHAVIOUR INDEX)

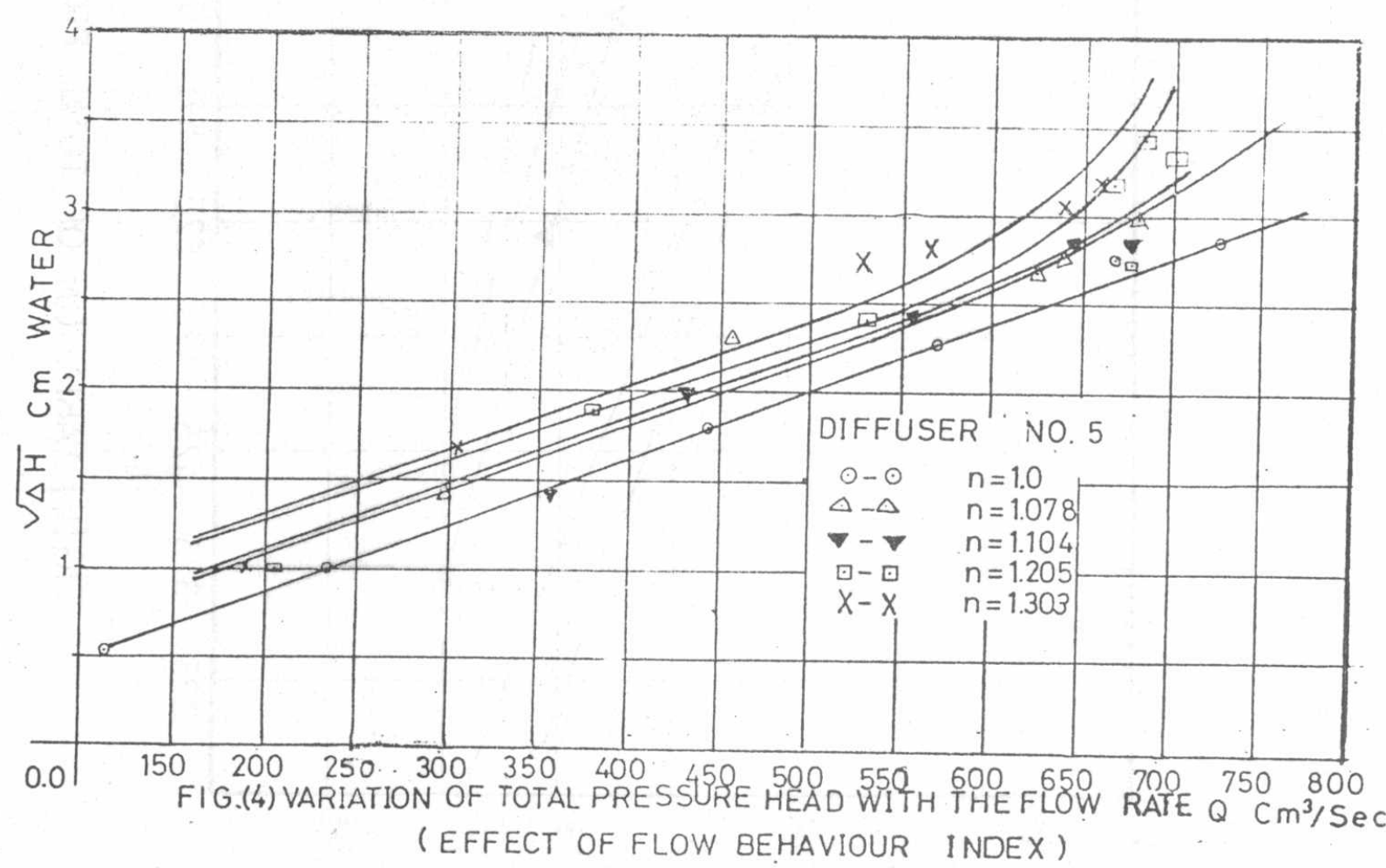

(EFFECT OF FLOW BEHAVIOUR INDEX) 


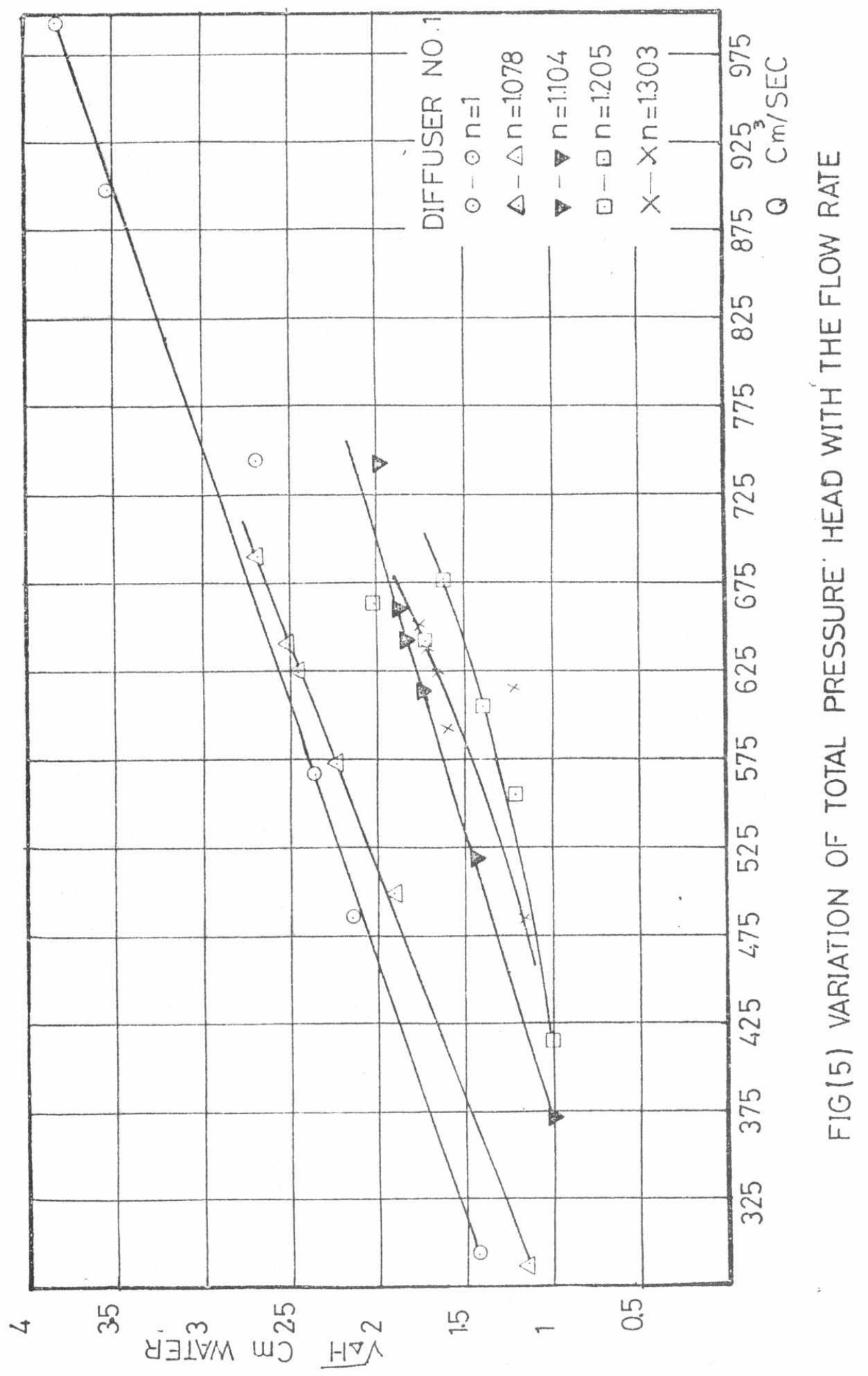


\begin{tabular}{|l|l|}
\hline FM-2 & 311 \\
\hline
\end{tabular}

FIRST A.S.A.T. CONFERENCE

14-16 May 1985 , CAIRO

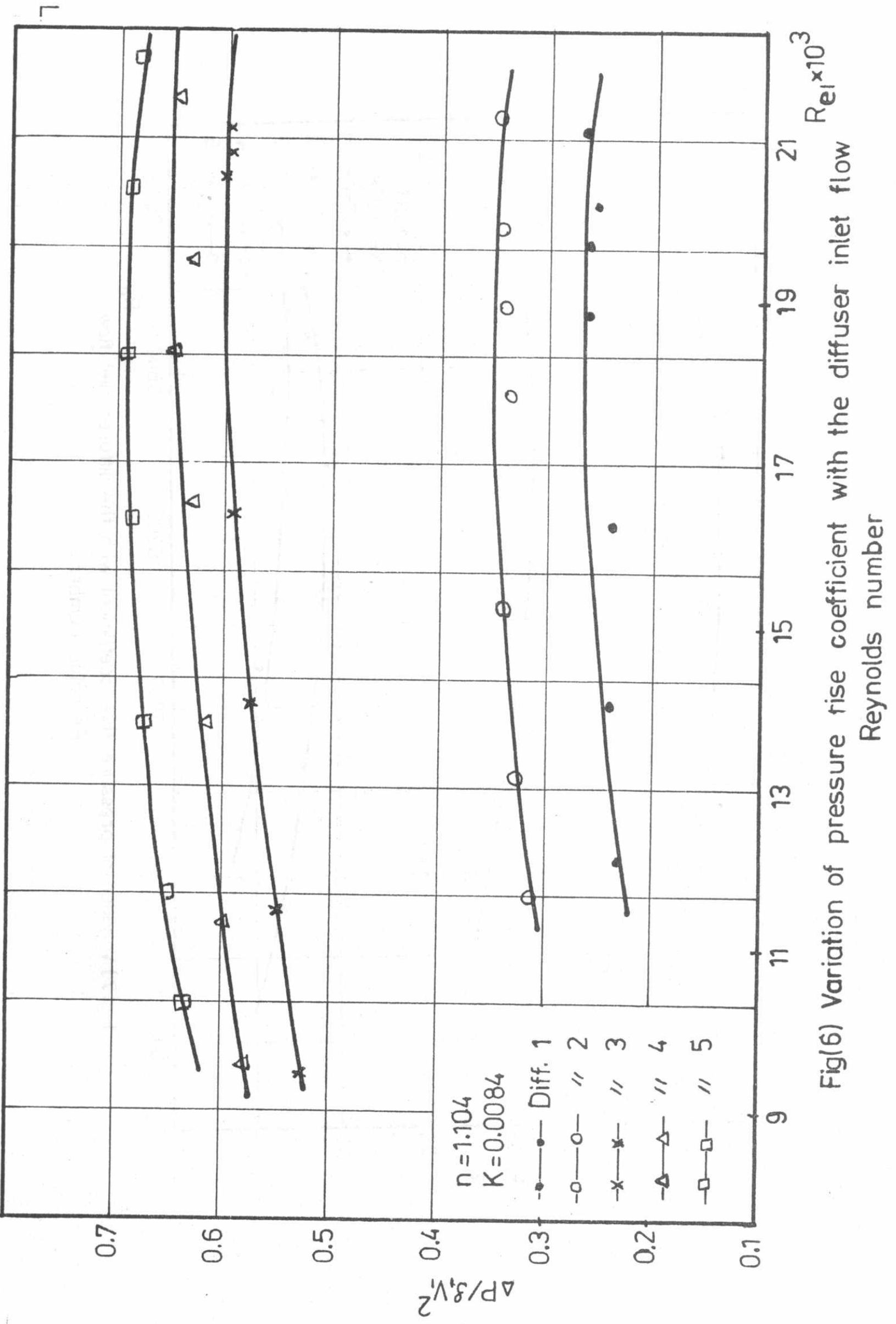




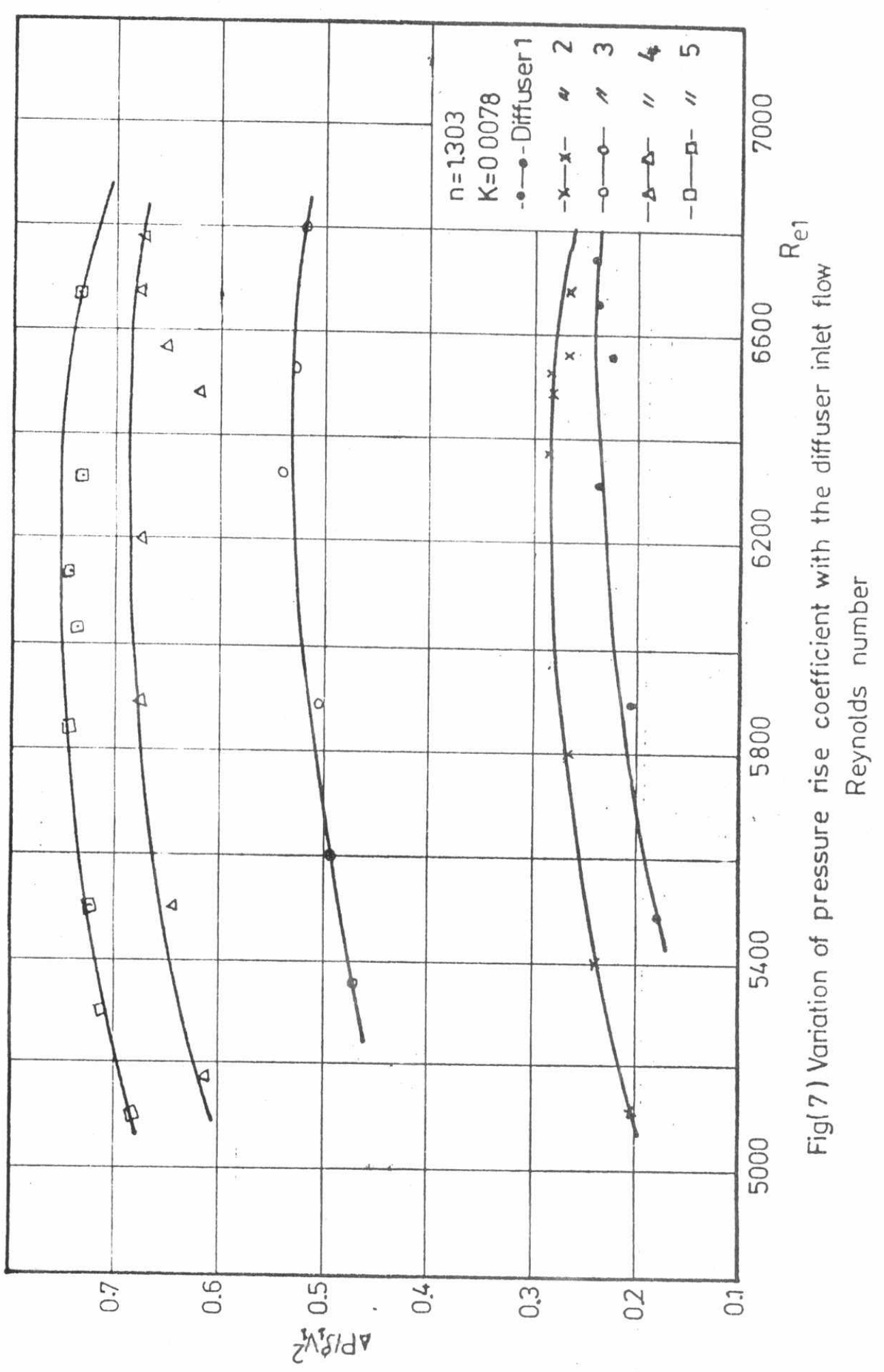

